\title{
Microbial contamination of denture polishing equipment
}

SADJ April 2019, Vol. 74 No. 3 p116 - p122

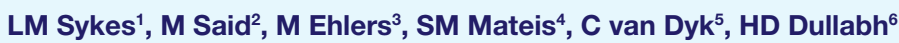

\section{ABSTRACT}

\section{Introduction}

Lathes and pumice slurry are commonly used without change or disinfection for polishing both new and old, repaired dentures.

\section{Purpose}

To identify and quantify any microorganisms harboured in these components in the laboratories of an academic teaching institution where the machines are in constant daily use.

\section{Material and methods}

Two machines were identified and labelled in each laboratory, one for exclusive use for new dentures and the other for dentures which had been exposed to any form of patient oral contact. Users were so informed.

Samples were collected twice daily on alternate days over a period of one week and tested for the presence and type of microorganisms, and whether the levels of contamination increased with usage.

\section{Results}

Pumice throughout was contaminated with a variety of bacteria, yeasts and moulds. notably Aspergillus, which will hover in the abundant aerosol during polishing. Cross-contamination can thus occur between dentures, posing danger to patients. Consultation between the dental staff and the Department of Medical Microbiology established a standardised disinfection protocol for the polishing wheels, machinery and pumice slurry.

Author affiliations:

1. Leanne M Sykes: BSc, BDS, MDent (Pros), Dip Res Ethics (Irensa), Dip ForOdont, Head Clinical Unit, Department of Prosthodontics, University of Pretoria, South Africa.

2. Mohammed Said: BSc, MBBCh, DTM\&H, FCPath (Microbiology), MMed (Microbiology), Senior Specialist, Department of Medical Microbiology, University of Pretoria, South Africa.

3. Martie Ehlers: BSc (Agric) Microbiology, BSc Hons (Agric) Microbiology, MSc (Agric) Microbiology, PhD Microbiology, Professor, Department of Medical Microbiology, Faculty of Health Sciences, University of Pretoria. Department of Medical Microbiology, National Health Laboratory Service, Tshwane Academic Division, South Africa.

4. Sipho M Mateis: BSc, (Microbiology), Postgraduate student, Department of Medical Microbiology, University of Pretoria, South Africa.

5. Charissa van Dyk: $B C h D$, Undergraduate dental student, University of Pretoria, South Africa.

6. Hemant D Dullabh: BChD, MSc(Dent), MDent (Pros), Head of Department of Prosthodontics, University of Pretoria. South Africa. Corresponding author: Leanne M Sykes

Department of Prosthodontics, University of Pretoria, P.O Box 1266 Pretoria 0001, South Africa. Email: leanne.sykes@up.ac.za

\section{Conclusion}

Prevention of cross contamination is crucial to avoid inadvertent but nevertheless culpable infection of denturewearing patients, as well as for personal protection.

\section{INTRODUCTION}

Poor infection control is a major problem in dental surgeries as it can result in both infection and possible cross-contamination of patients, dentists and laboratory technicians. As far as possible all materials and equipment used in dental practices and laboratories should be meticulously disinfected and/or sterilised between each patient. However, some procedures may inadvertently be overlooked and could pose a threat of cross contamination. This is a particular concern when clinicians move between chairside and laboratory settings such as while adjusting, polishing and inserting dental prostheses. ${ }^{1}$

Many dentists, technicians and students at academic teaching institutions and private dental practices and laboratories use the same denture polishing lathes, pumice slurry and polishing waxes in the laboratory for polishing both new and old dentures, without any of these being disinfected or changed between uses.

This study aimed to investigate whether the pumice and polishing wheels harboured microorganisms, if so to identify and quantify them, and then to develop a disinfection protocol to prevent possible crosscontamination between patients.

\section{LITERATURE REVIEW}

Dental pumice consists of a powdered form of first grade volcanic rock, resulting in a fine, light and porous abrasive. It comes in fine, medium and coarse grades, all of which are mixed with water to the desired consistency. ${ }^{2}$

It is used as a cleaning and polishing aid to finish acrylic resin dentures, and also in toothpastes, polishing compounds and other dental prophylactic oral hygiene pastes. The gritty texture of pumice helps smooth the acrylic resin by removing scratched or pitted areas on denture and tooth surfaces that could harbor plaque and bacteria. It can also be used to polish off surface staining such as those produced by certain foods, drinks and smoking. 
Advantages of pumice are that it is readily available, has a neutral $\mathrm{pH}$, is chemically benign, hard enough to abrade, yet soft enough not to damage the surface, and has a friable property allowing it to be ground down to an ultrafine powder that still retain its abrasive qualities. This makes it ideal for use where the quality and smoothness of the finished surface is of utmost importance. ${ }^{3}$ Other abrasives used in dentistry include aluminium oxide to deflash crown work, glass beads to aid autoclave sterilization of implements at high temperature, and calcium carbonate as an abrasive in smokers' toothpastes. ${ }^{4}$

Polishing of dentures is accomplished by using a pumice slurry with spiral sewn cotton wheels in a polishing lathe. The plies of cotton cloth are sewn together spirally, making the wheels much harder, which allows more pressure to be exerted on them during the polishing process. This also makes them durable and long lasting so replacement is necessary only after many cycles of use. The cotton plies are also pre-raked to accept the pumice slurry. Final shine is achieved using the same lathe system and cotton wheels, but replacing the pumice with a denture polishing compound. Many studies have been conducted assessing the presence of microorganisms in dental polishing lathes, pumice, polishing cloths, and in the aerosol created from backscatter during polishing. ${ }^{1}$

As far back as 1968, Lorato suggested mixing a chemical disinfectant into the slurry water of the pumice polishing medium. ${ }^{6}$ However, this still did not address the possibility of organisms remaining on the polishing cloths which are seldom changed between patients and in particular those used for the final high polish where wax is used as opposed to pumice.

Kahn et al (1982) found massive microbial growth on new dentures polished after the lathe had been used to re-polish 12 old dentures. This was reduced by $75 \%$ when the old dentures were first scrubbed for one minute with 3\% hexachlorophene cleanser, and by almost 99\% when the new dentures were also scrubbed with hexachlorophene after polishing. ${ }^{1}$ This simple experiment illustrated how easily pathogenic organisms could be transferred from patient to patient after simply polishing dentures. It is an unacceptable risk in dentistry as organisms such as non-haemolytic streptococci, lactobacillus, Neisseria, diptheroids, B haemolytic streptococci, Staphylococcus aureus, Escherichia coli and candida albicans have all been isolated from this equipment. ${ }^{1}$ This poses a possible risk for cross-contamination between dental laboratory staff, clinicians and patients which could result in significant epidemics of communicable diseases depending on the number and types of organisms, patient populations and host resistance..$^{1,6}$

Cross-contamination can occur through aerosol formation during the pumicing and polishing of dentures and by direct denture and skin contact during handling, especially as many clinicians and most technicians work without gloves in the laboratory areas. ${ }^{7}$ Water and organic matter such as plaque and skin scales can act as nutrients for bacteria and contribute to their growth within the pumice, making this ideal for bacterial growth, and possibly a conduit for their transfer between patients during the polishing. ${ }^{7,8}$ Setz found used pumice to be contaminated with bacteria from the oral cavity, non-oral bacteria and fungi, and that the contamination was drastically reduced when sterilized pumice and wheels were used. ${ }^{6}$

Williams et al. (1983) tested pumice from two commercial dental laboratories where old pumice was not replaced, but merely added to as needed. They isolated Acinetobacter, Pseudomonas and Alcaligenes, with the Acinetobacter being the main contaminant. ${ }^{9}$ This is a concern as this organism has been associated with various infections ranging from mild to life threatening, including pneumonia, septicaemia, meningitis, endocarditis, eyeinfections and head and neck infections. It is also resistant to certain chemical disinfectants such as quaternary ammonium compounds. ${ }^{9}$

Verran et al. found that pumice disinfected with chlorhexidine gluconate and used with a rag wheel that had been immersed in chlorhexidine gluconate for one minute, resulted in a significant decrease in contamination. The levels of contamination began to rise again after 24 hours, particularly Pseudomonas spp, Staphylococci, Bacillus spp, and a few fungi. ${ }^{7}$ In a similar study, dentures were immersed in hypochlorite for 10 minutes before pumicing, but it was still found that after three days of lathe use, the levels of microbial contamination were considerable, especially for Staphylococcus, Candida, Pseudomonas and Micrococcus. This could be because the hypochlorite reduces the microbial load on the dentures but does not actually destroy them. ${ }^{7}$

Williams et al. identified Bacillus, Acinetobacter, Micrococcus, Pseudomonas, Moraxella and Alcaligenes, as well as $A$. calcoacoaceticus and $P$. maltophilia in dental pumice. A concern was that the latter two were both resistant to polymyxin $\mathrm{B}$ sulphate and penicillin. The most consistently isolated micro-organisms were aerobic, Gram negative bacilli, which are known opportunistic pathogens that can contaminate dentures and lead to bacterial colonization of the oropharynx. This in turn increases patients' risk for pneumonia, especially if they are also immune-compromised. In addition, bacilli can infect a patient by entering open wounds associated with the process of immediate dentures, and increase their risk of developing bacterial endocarditis. ${ }^{8}$ They also found high levels of non-oral micro-organisms which are capable of surviving in pumice for many months. These can be transferred from skin and hands to the pumice and then from the pumice to the denture wearer and vice versa. ${ }^{8}$

Other studies isolated Gram-positive bacilli, Streptococci spp, Staphylococcus aureus, S epidermis, B catarrhalis and Neisseria sicca from dental pumice. The replacement of tap water by Virkon yielded significantly lower bacterial counts leading to the conclusion that "bacterial contamination originates from the tap water, the atmosphere, the appliance and the clinician". ${ }^{10}$ Fungi have also been isolated in particular Aspergillus and Fusarium spp. These are opportunistic pathogens and may produce disease in the immune-compromised patient. Aspergillus flavus and Aspergillus niger are most frequently involved in 
human infections. Aspergillus spp not only pose a risk for possible infection but can contribute to allergic exposure and toxic manifestations. ${ }^{11}$ Pumice aerosols are equally dangerous. They may contain Moraxella and Acinetobacter species which are associated with conjunctivitis. ${ }^{8}$

Recommendations from many sources are to use fresh pumice for each patient, cleanse pumice pans with a disinfectant between patients (or use disposable dishes and discard them after use) and autoclave pumice wheels between patients. The wax may be more difficult to control as it's not possible to use new blocks for each patient, and alternative methods of disinfection must be investigated. Considering that dentists have been aware of possible cross contamination for over 50 years, and that many safety precautions have been documented, it was alarming for the researchers to notice that in the dental laboratories of a large teaching hospital, there was no means of disinfection of this machinery and material. Following this observation, an informal "snapshot" survey of other universities was conducted as well as of random private practices and laboratories. This revealed a diverse range of conditions ranging from excellent to disastrous (Figure 1).

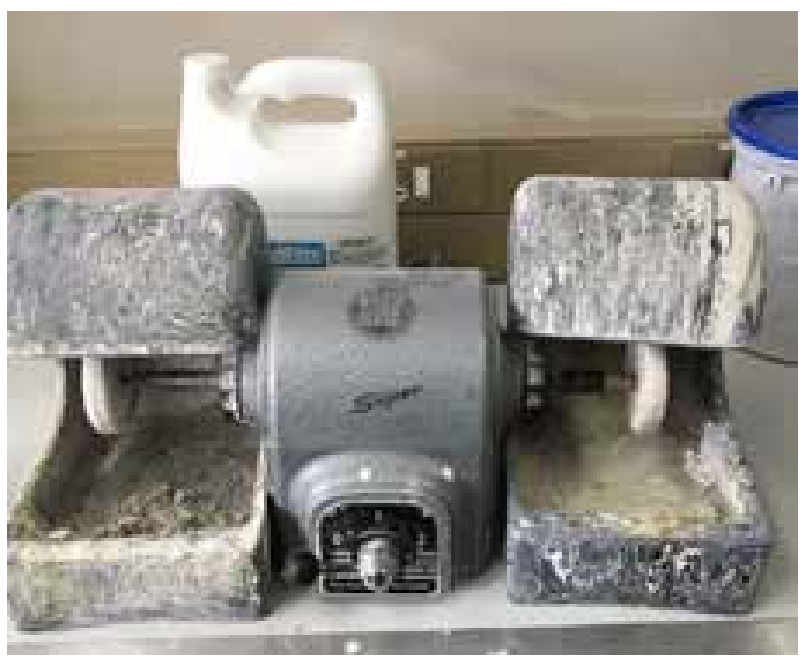

Figure 1. Conventional lathe polishing machines from various teaching institutions and laboratories within South Africa and the United Kingdom.

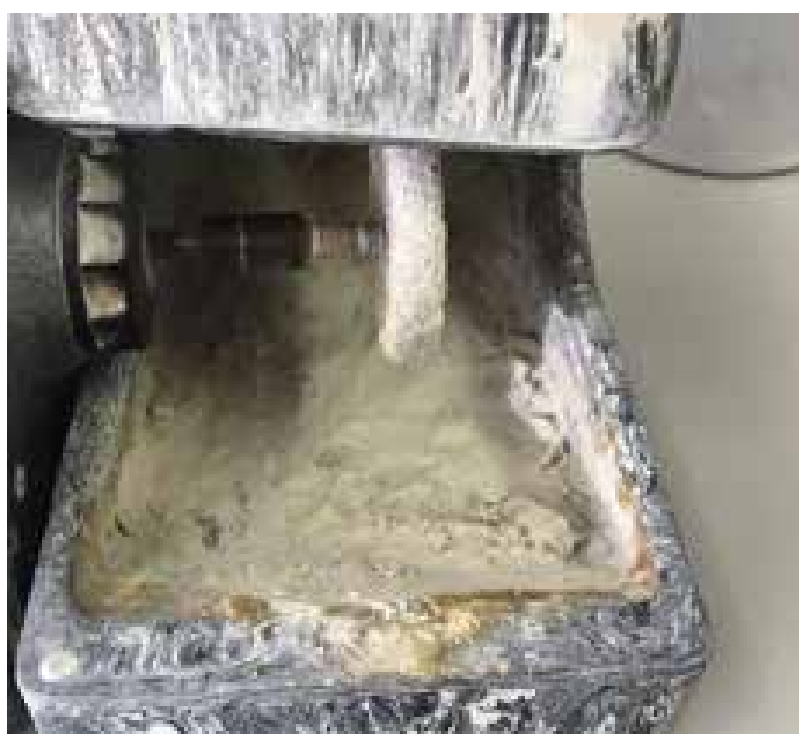

Figure 2. Rag wheel with pumice slurry where samples were collected.
Given the high incidence of hepatitis, TB, and HIV in South Africa, this situation becomes even more worrying. In 2016, the reported prevalences of HIV in South Africa were: $22.3 \%$ in women $15-49$ years old; $18,9 \%$ in $15-49$ year old adults; $5.6 \%$ in youth between 15 and 24 years. The estimated prevalence of HIV in the total population is $12.7 \%$, i.e. over 7.03 million people. ${ }^{12}$

\section{AIM AND OBJECTIVES}

The aim of this study was to establish whether potentially pathogenic microorganisms could be recovered from denture polishing equipment, and if so, to isolate and identify these organisms from the pumice slurry and on the polishing wheels.

The objectives of this study were to:

- To take samples of the pumice slurry and from the polishing cloths used to polish new and old dentures from a selection of dental laboratories in South Africa. To identify and quantify the selected microorganisms using phenotypic and biochemical methods.

- To investigate current literature and to establish which disinfection protocols are recommended for the different organisms identified.

- To make recommendations and implement a suitable protocol for cleaning and disinfection of the dental equipment investigated in this study.

- To inform and advise dental colleagues and technicians in private practice who may not be aware of the need for a meticulous disinfection protocol for their polishing equipment, as well as other less obvious items and materials.

\section{MATERIALS AND METHODS}

The investigation was conducted in collaboration with the Department of Medical Microbiology, using polishing equipment in selected student dental laboratories and technician's production laboratories.

\section{Sample collection}

Samples were collected from the rag wheel and pumice slurry from two denture polishing machines in each laboratory area. One machine was used only for new dentures, and the other for dentures that had been in contact with the mouths of patients (Figures 1 and 2).

Culture identification and storage of samples In brief, the following microbiological aspects of organism isolation, culture and identification were undertaken: The serial dilution method with peptone saline diluent (PSD) at ambient temperature was used for all initial dilutions. Specimens from each dilution were cultured on blood, MacConkey and Sabouraud's dextrose agar plates.

A Gram-stain of each cultured isolate was also performed according to the methods outlined in Brock Biology of Microorganisms (Madigan et al., 2015). The cultured colonies were then quantifed and identification and antimicrobial susceptibility of the colonies was performed using the Vitek 2 instrument (bioMerieux, France).

Isolates identified as E.coli, staphylococci, Pseudomonas aeruginosa and Candida species then all had their DNA 
extracted using the ZR Fungal/Bacterial DNA Miniprep ${ }^{\mathrm{TM}}$ commercial kit (Zymogen Fermentas, USA) according to the manufacturer's instructions in order to obtain ultra-pure DNA. The species of the specific genes under investigation were identified using multiplex PCR (M- PCR) assays.

\section{Statistical analysis of results}

Analysis of the microbiological data was carried out in collaboration with the biostatistician of the Biostatistics unit, Medical Research Council, Pretoria.

The statistical analysis was predominantly summary statistics presenting proportions and associated confidence intervals of the estimates for identified microorganisms. STATA 13 was used for the data analysis.

\section{RESULTS}

The results revealed that the pumice and polishing wheels of all the machines were colonized with a large variety and volume of bacteria, yeasts and moulds, with higher colony counts in the pumice than on the wheels (Figure 3).

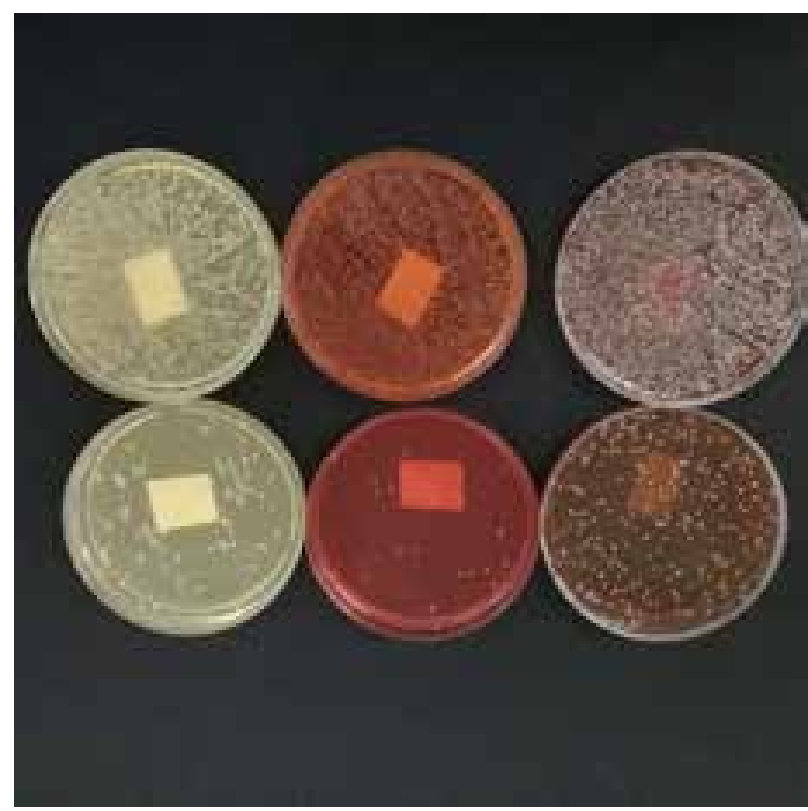

Figure 3. Culture plates from the pumice (top row) and wheels (bottom row).

Bacterial organisms included Aerococcus viridans, Enterobacter cloacae complex, leclercia adecarboxylata, Moraxella group, Pantoea spp, Pseudomonas putida, Sphingomonas paucimobilis. Bacillus spp, Micrococcus spp, Streptococci, Staph. Aureus, and aerobic gram negative bacteria. Most of the yeast isolates belonged to genus Rhodotorula glutinitis, with the most predominant moulds being Aspergillus niger.

The Streptococci were mostly found on the polishing wheels, while the Staph. Aureus, and aerobic gram negative bacteria were isolated from the wet pumice. Most of these organisms are normal oral flora, however, the aerobic gram negative bacteria are gut flora often carried by immunocompromised individuals. There were no lactobacilli or Candida species present in any of the samples tested.

\section{DISCUSSION}

Any instrument or equipment used in the mouth, or that comes into contact with the oral environment is a potential source of cross-infection. ${ }^{13}$ It is impossible to determine the patient's state of infectivity based on their medical and dental records, physical or oral appearance, socioeconomic status or verbal questioning. Thus one must assume that all patients are capable of transmitting highly infectious diseases and act accordingly. ${ }^{13}$

This study investigated the microbial contamination of one isolated item of clinical and laboratory equipment, the polishing lathe and pumice. Use of the lathe provides a high risk for the spread of infection as "The rotary action of the wheels, stones, brushes and rags generate aerosols, spatter and projectiles". ${ }^{13}$

The Aerococcus viridans are Gram-positive cocci which may cause urinary tract infections, bacteraemia, endocarditis, para-aortic abscess, meningitis, spondylodiscitis and septic arthritis. The risk of infection is increased in persons with granulocytopenia, oral mucositis, prolonged hospital stays, previous antibiotic therapy, invasive procedures and implantation of foreign bodies. As such these are a potential danger to many dental patients especially those who have undergone recent osseointegrated implant placement, and more so if the procedure had involved hospitalisation and follow-up antibiotics. ${ }^{14}$

The Enterobacter cloacae complex consist of rod shaped Gram-negative bacteria commonly found in terrestrial and aquatic environments (water, sewage, soil and food). They occur as commensals in human and animal intestinal tracts. They may be responsible for nosocomial infections including bacteraemia, lower respiratory tract, urinary tract, and intra-abdominal infections as well as endocarditis, septic arthritis, osteomyelitis and skin and soft tissue infections. ${ }^{15}$ Their importance in this study is that the skin and Gl tract are the most common sites through which they can be contracted. This makes them dangerous for clinicians or technicians who have skin abrasions or cuts in using contaminated pumice and lathes. ${ }^{16}$

Leclercia adecarboxylata is a motile Gram-negative bacillus that was first isolated from drinking water and is distributed widely in the environment especially in food and water, as well as from various clinical specimens including blood, faeces, sputum, urine and wound pus. ${ }^{17}$ Infections occur most commonly in immunocompromised patients or those with other infections suggesting its dependence on co-flora to cause disease. ${ }^{18}$ It may be a danger to elderly and immunocompromised dental patients, especially those with HIV or undergoing any form of cancer therapy. Moraxella is also a Gramnegative rod found in normal oropharyngeal flora. It may cause lower respiratory tract infections, and otitis media. In the latter, it usually forms part of a mixed culture of pathogens along with Haemophilus influenza and Streptococcus pneumonia. ${ }^{19}$ Pantoea is a genus of Gram negative bacteria of the family Enterobacteriaceae. They are rare organisms which may occasionally be isolated from diverse clinical specimens, including blood, sputum, urine, cerebrospinal fluid, joint 
fluid, bile, and wounds. As with Leclercia adecarboxylata, they are significant in dentistry as they tend to infect compromised hosts or those undergoing invasive procedures or insertion of foreign bodies. Fortunately, they are fairly susceptible to all classes of antimicrobials. ${ }^{20}$ Pseudomonas putida is a rod shaped, flagellated, Gram negative bacterium that is found in most soil and water habitats where there is oxygen, and was thought to be of low pathogenicity. However, over the last three decades, these have increasingly become significant human pathogens particularly in hospital settings. They colonize moist and inanimate hospital surfaces, causing nosocomial infections, especially in immunocompromised patients and those with medical devices or catheters. ${ }^{21}$

Sphingomonas is a rod shaped Gram negative, non-spore forming, chemoheterotrophic, strictly aerobic bacterium that has been associated with a variety of infections in humans, including bacteraemia, pneumonia, catheter related infections, meningitis, peritonitis, osteomyelitis, septic arthritis, postoperative endophthalmitis, lung empyema, splenic abscesses, urinary tract infections, and biliary tract infections. They too are rare but increasingly are being seen in clinical settings. ${ }^{22}$

Bacillus is a genus of gram-positive, rod-shaped bacteria and a member of the phylum Firmicutes. Bacillus species can be obligate aerobes, or facultative anaerobes. They can cause food poisoning, localized infections related to trauma, deep seated soft tissue infections, and systemic infections (meningitis, endocarditis, osteomyelitis, and bacteraemia). Fulminant eye infections are widely recognized complications of non-anthrax Bacillus infections, most commonly $B$. cereus. The various species implicated in serious infections include $B$. cereus, $B$. subtilis, B. sphaericus, B. alvei, B. laterosporus, B. licheniformis, $B$. megaterium and $B$. pumilus. Micrococcus is ubiquitous, being found in water, dust and soil. It is thought to be a commensal organism, though it can be an opportunistic pathogen, particularly in hosts with compromised immune systems, such as HIV patients..$^{23}$ It can be difficult to identify Micrococcus as the cause of infection since the organism is normally present in skin microflora and the genus is linked to diseases. In rare cases, death of immunocompromised patients has occurred from pulmonary infections caused by Micrococcus. Micrococci may be involved in other infections including recurrent bacteraemia, septic shock, septic arthritis, endocarditis, meningitis and cavitating pneumonia, especially in immunocompromised patients. ${ }^{24}$

Rhodotorula glutinitis was the most predominant yeast isolated. It belongs to a genus of unicellular pigmented yeasts, and is easily identifiable by its distinctive orange/red colonies when grown on Sabouraud's Dextrose Agar (SDA). Rhodotorula is a common environmental yeast that is found in air, soil, lakes, ocean water, milk, and fruit juice. This yeast has a strong affinity for plastic, and is often isolated from medical equipment, such as dialysis equipment, fibre-optic bronchoscopes, and other surfaces such as shower curtains, bathtubs, and toothbrushes. It is particularly dangerous in clinical settings as it is an opportunistic pathogen which can readily colonise and infect susceptible patients. The mould Aspergillus niger was also isolated. Although
Aspergillus spp are ubiquitous moulds in the environment, they can cause disease, particularly in immunocompromised hosts. The organisms are usually inhaled making their presence in the pumice a concern as this machine is known to produce large volumes of aerosol splatter during use. They may cause respiratory tract infections, mycetomas, orbital and sinus infections, ear infections, and even more invasive disease like infective endocarditis.

To avoid cross-infection from this equipment the following precautionary measures should be implemented whenever they are in use: the front shield should be in place and a ventilating system in operation; the operator should wear a protective face mask and goggles; fresh pumice and clean water should be used for each new patient; a small amount of pumice should be dispensed into either a disposable container that can be discarded after use or a flat dish that can be cleaned and disinfected; used pumice should be disposed of in a suitable hazard bin and not down the drain where it can cause blockages; rag wheels, stones and brushes should be rinsed, disinfected and heat sterilized (boiled in water) after each patient; and all other items wiped down with a suitable surface disinfectant (Fig 4). ${ }^{13}$

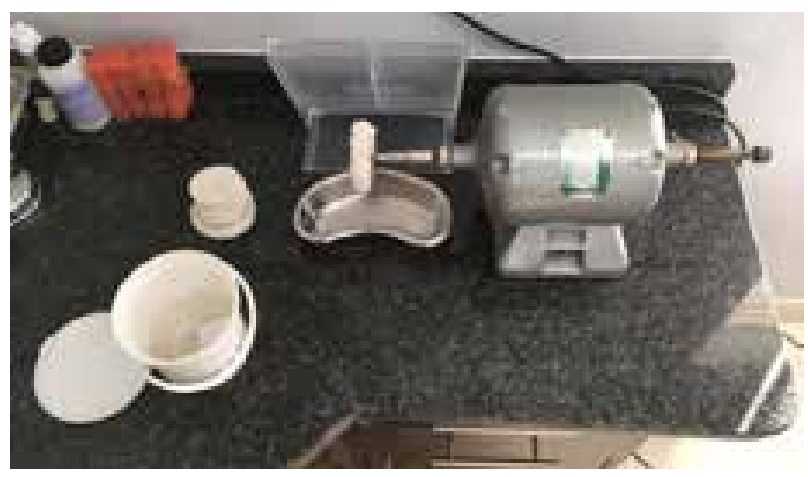

Figure 4. The ideal scenario (courtesy Prof Bernitz).

There can be no doubt that there are many more potentially risky areas of cross-contamination that could go unnoticed. Presumably this is due to oblivion and complacency rather than intentional negligence or disregard for protocol. However, all personnel working with patients need to become more sensitised and alert to areas where possible cross-infection could occur. Awareness should then be followed by Action to rectify the situation, because cross-infection cannot be reversed! The list on $\mathrm{p} 121$ is by no means exhaustive, but rather presents examples of latent situations, often overlooked, that could pose a threat of cross-contamination, and suggests some practical solutions for each.

Whenever possible, a third, ungloved person who has had no contact with the patient should handle commonly used items that may be difficult to disinfect or neglected such as cameras, computer keyboards, X-Ray buttons, patient files, and cellular phones. Where not possible, the clinician should remove gloves when handling them. In addition there needs to be effective communication and coordination of disinfection practices between the clinician and the laboratory to help ensure the performance of the appropriate cleaning and disinfection procedures by each, without omissions or unnecessary duplication, and to provide that there is no damage to any of the transferred materials during this process. ${ }^{13}$ 
All items coming from or going to the oral cavity must be sterilized or disinfected before work starts on them in the laboratory, and again before their next contact with the patient. ${ }^{13}$ Note, clean, disinfected and sterile are not one and the same, and even though items may have been cleaned, they are not necessarily disinfected or sterile and should still be handled with care. Cleaning involves the physical removal of visible debris, blood and bioburden which could isolate and protect micro-organism from sterilizing agents.

Disinfection refers to "the process of removing pathogenic organisms from instruments and equipment by the use of a disinfectant. It may be achieved by using moist heat (washing and rinsing in water at $70^{\circ} \mathrm{C}-90^{\circ} \mathrm{C}$ will kill most non-sporing micro-organisms), ultraviolet radiation, filtration, gases, and chemical disinfectants." Sterilisation is "the process by which all types of microorganisms are destroyed, including spores and vegetative micro-organisms. ${ }^{25}$ Impressions, appliances and prostheses should ideally be cleaned and disinfected as soon as they are removed from the oral cavity before the blood and biofilm dries out.

The procedure involves rinsing, spraying with, or immersion in an appropriate intermediate-level disinfectant for the recommended contact time, followed by repeat rinsing. Thereafter they may be handled and/or transferred.The same applies to instruments, however, it is often more convenient and easier to clean and sterilize these later.

\section{CONCLUSIONS}

Dental clinicians, staff and laboratory personnel need to be more aware of the many potential sources of microbial contamination and potential cross infection when handling materials that have been in contact with the oral environment. The American Dental Association (ADA) has categorized patient care items as critical, semicritical and non-critical based on their risk of infecting patient during use. They also offer in-depth guidelines for the cleaning, disinfection and sterilization of each. ${ }^{26}$

All those involved in treating dental patients should re-visit, on a regular basis, these or other similar protocols, such as those issued by the HPCSA, ${ }^{27}$ the Dental Council of Dublin, ${ }^{28}$ or the Centre for Disease Control (CDC), ${ }^{29}$, and update themselves when necessary. They should also implement stringent disinfection and sterilization protocols in their surgeries, and be vigilant that all staff adhere to these.

\section{Ethical consideration and conflict of interest}

The protocol gained approval from the Research Committee of the Dental School (RESCOM) as well as the Research Ethics Committee of the Faculty of Health Sciences. Funding was provided by the Department of Medical Microbiology and there was no conflict of interest to declare.

\begin{tabular}{|c|c|}
\hline Item/Situation & Suggested Solutions \\
\hline Indelible pencil & $\begin{array}{l}\text { These are seldom considered sources of cross contamination and are often placed in drawers or other areas for } \\
\text { easy access without being disinfected between use (Fig 5). They should either be cleaned with a surface disinfec- } \\
\text { tant and then rinsed and autoclaved between uses, or preferably use disposable sticks such as "Dr Thompson's } \\
\text { sanitary colour transfer applicators" Available in S.A. from pdeville@global.co.za . Expensive but worth it. }\end{array}$ \\
\hline Computer keyboard & $\begin{array}{l}\text { Cover with a layer of cling-film and wipe down with a surface disinfectant between patients or change the plastic } \\
\text { (Fig 6). The mouse is more difficult to protect without making it impossible to manipulate. At least it should be wipe } \\
\text { with a surface disinfectant between use. }\end{array}$ \\
\hline $\begin{array}{l}\text { Gas knobs; X-Ray unit } \\
\text { buttons; X-Ray sensors }\end{array}$ & $\begin{array}{l}\text { The first two are often forgotten and should be wiped with a surface disinfectant after use. Plastic disposable } \\
\text { covers should always be used on the X-Ray sensors and discarded after use. Other radiographic accessories that } \\
\text { have made contact with the mouth, blood or saliva should be disinfected or heat sterilized if possible. }\end{array}$ \\
\hline Patient record files & $\begin{array}{l}\text { Ideally the dentist should read notes and treatment plans before seeing the patient and putting on gloves, and also } \\
\text { only fill in the files after completion of treatment, again ungloved. (In reality, some busy clinicians may only open and } \\
\text { consult these during treatment which could contaminate them). Ideally files should be kept in plastic covers which } \\
\text { can be wiped clean with a surface disinfectant. }\end{array}$ \\
\hline $\begin{array}{l}\text { Fox plates, endodontic } \\
\text { file rulers }\end{array}$ & These should all be autoclaved between use \\
\hline Tooth shade tabs & $\begin{array}{l}\text { These cannot be autoclaved but the individual tabs used need to be wiped with a surface disinfectant after use. NB } \\
\text { make sure the disinfectant used does not stain or alter their shade. }\end{array}$ \\
\hline $\begin{array}{l}\text { Cotton wool dispens- } \\
\text { ers, Vaseline, pressure } \\
\text { indicating paste etc. }\end{array}$ & $\begin{array}{l}\text { Wipe down the dispensers with a surface disinfectant between every patient, or alternatively use sterile pre-packed } \\
\text { rolls and balls. Vaseline should never been taken directly from the tub with gloved or ungloved fingers, but rather } \\
\text { use an instrument kept for this purpose. A better situation is to prepare individually dispensed and wrapped por- } \\
\text { tions of Vaseline, pressure indicating paste etc. (Fig 7). }\end{array}$ \\
\hline Acrylic laboratory burs & $\begin{array}{l}\text { These should be treated in the same manner as burs used intra-orally and not shared between patients. They } \\
\text { should be washed, placed in cold sterilizing solution and then autoclaved. }\end{array}$ \\
\hline $\begin{array}{l}\text { Wax polishing blocks, } \\
\text { impression adhesive } \\
\text { brushes }\end{array}$ & $\begin{array}{l}\text { Some items are impossible to clean or disinfect, and impractical to discard after single use. In these situations the } \\
\text { dentures and special trays themselves should be disinfected after removal from the mouth, rinsed, dried and then } \\
\text { polished or painted }\end{array}$ \\
\hline $\begin{array}{l}\text { Biopsy specimen } \\
\text { bottles }\end{array}$ & $\begin{array}{l}\text { These are almost always handled with gloved, often bloodied hands. They should be wiped with a surface disinfec- } \\
\text { tant before sending out to the pathology laboratory }\end{array}$ \\
\hline $\begin{array}{l}\text { Cameras, telephones, } \\
\text { cellular phones }\end{array}$ & Ideally a third, ungloved person who has no contact with the patient should handle these. \\
\hline
\end{tabular}




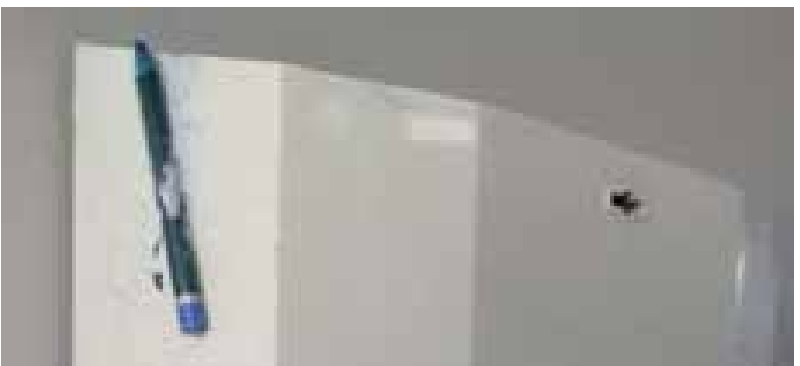

Figure 5.

Indelible pencil attached to paper towel dispenser with Pres-tik for "easy access".

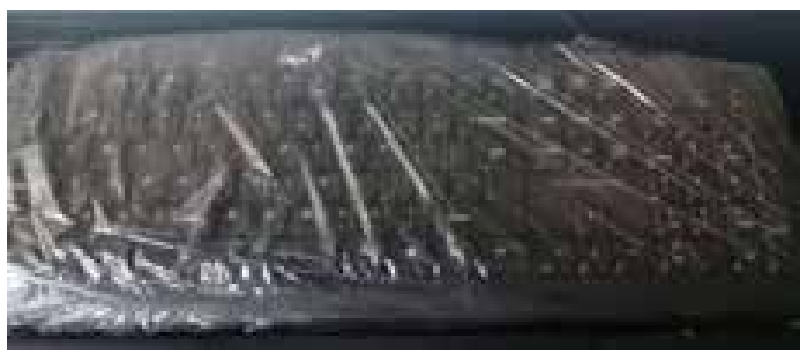

Figure 6. Computer keyboard covered with cling-film.

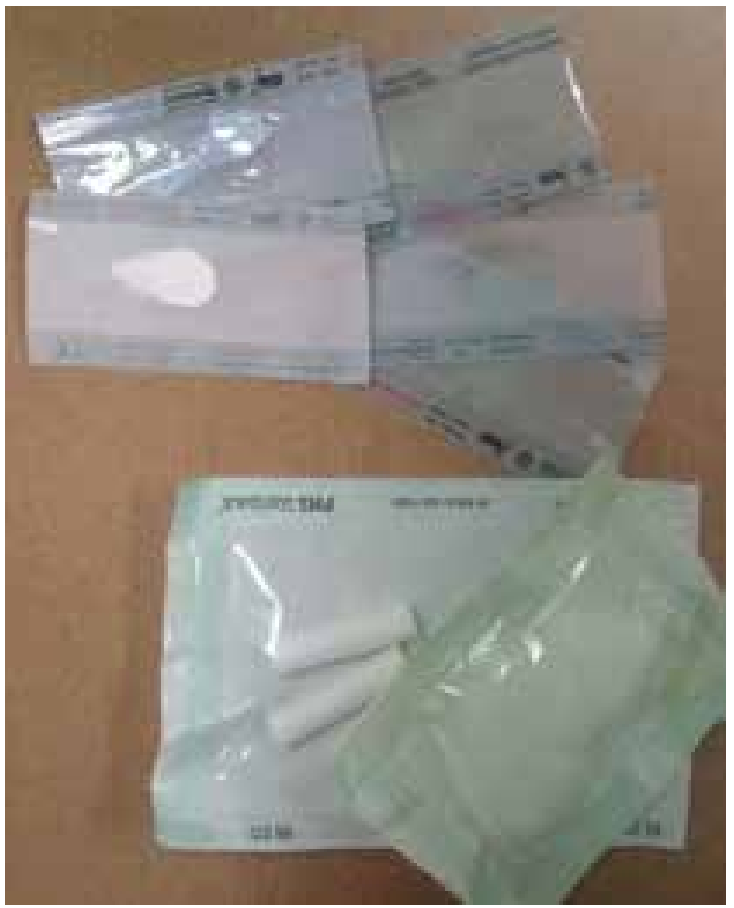

Figure 7. Individually packaged Vaseline, pressure indicating paste and cotton wool.

\section{References}

1. Kahn RC, Lancaster MV, Kate W. The microbiologic crosscontamination of dental prostheses.

J Prosthet Dent. 1982;47:556-9.

2. Kerr Dental. Accessed at https://www.kerrdental.com/kerr-laboratory/pumice-sundries; Accessed on: 16-02-2017.

3. Hess. Pumice powder is a gentle polishing abrasive and cleanser. Accessed at: hesspumice.com/pumice-pages/ pumice-uses/polishing-abrasives.html;

Accessed on: 16-02-2017.

4. Techfil. Dental pumice treatments Accessed at: www.techfil. co.uk/markets/dental-treatments; Accessed on: 16-02-2017.

5. Lorato DC. Disinfection of pumice. J Prosthet Dent. 1968;18:534.

6. Setz J, Heeg P. Disinfection of pumice. J Prosthet Dent.1996;76:448-50.
7. Verran. J, Winder C, Fraser McCord J, Maryan CJ. Pumice. Slurry as a crossinfection hazard in nonclinical (teaching) dental technology laboratories. Int J Prostho.1997;10:283-6.

8. Williams H, Falkler W, Hasler J, Libonati J. The recovery and significance of non-oral opportunistic pathogenic bacteria in dental laboratory pumice. J Prosthet Dent. 1985;54:725-30.

9. Williams H, Falkler W, Hasler J. Acinetobacter contamination of laboratory dental pumice. J Dent Res. 1983;62:1073-5.

10. Witt S, Hart P Cross-infection hazards associated with the use of pumice in dental laboratories. J Dent. 1990;18:281-3.

11. Williams $H$, Falkler $W$, Smith $A$, Hasler J. The isolation of fungi from laboratory dental pumice. J Prosthet Dent. 1986;56:737-40.

12. Statistics South Africa. Mid-year population estimates 2016. Accessed at: http://www.statssa.gov.za/publications/P0302/ P03022016.pdf; Accessed on: 28-07-2017.

13. Dentistry Today. Dental laboratory asepsis. Accessed at: www.dentistrytoday.com/infection-control/1325; Accessed on: 22-06-2017.

14. Zhou W, Nanci V, Jean A, Salehi AH et al. Aerococcus viridans native valve endocarditis. Can $\mathrm{J}$ of Infectious Diseases and Medical Microbiology. 2013;24:155-8.

15. Barnes B, Wiederhold NP, Micek ST, et al. Enterobacter cloacae ventriculitis successfully treated with cefepime and gentamicin: case report and review of the literature. Pharmacotherapy: The $\mathrm{J}$ of Human Pharmacology and Drug Therapy. 2003;23:537-42.

16. Dalben M, Varkulja G, Basso M, et al Investigation of an outbreak of Enterobacter cloacae in a neonatal unit and review of the literature. J of Hospital Infection. 2008;70:7-14.

17. Keren $\mathrm{Y}$, Keshet $\mathrm{D}$, Eidelman $\mathrm{M}$ et al. Is Leclercia adecarboxylata a new and unfamiliar marine pathogen? J Clin Microbiology. 2014;52:1775-6.

18. Tam V, \& Nayak S. Isolation of Leclercia adecarboxylata from a wound infection after exposure to hurrican-related floodwater. BMJ case reports. 2012; bcr-2012-007298.

19. Ryan K, \& Ray CG. Sherris Medical Microbiology. New York: McGraw-Hill Education/Medical; 2014

20. Jameson. JLJ. Harrison's Principles of Internal Medicine. Accessed at: http://accessmedicine.mhmedical.com/content aspx; Accessed on: 03-08-2017.

21. Kim. S, Park SH, Park HB, et al. Nosocomial Pseudomonas putida bacteremia: high rates of carbapenem resistance and mortality. Chonnam Medical Journal. 2012;48:91-5.

22. Lin. J-N, Lai C-H, Chen Y-H, et al. Sphingomonas paucimobilis bacteremia in humans: 16 case reports and a literature review. Journal of Microbiology, Immunology and Infection.2010;43:35-42.

23. Smith K, Neafie R, Yeager J, Skelton $H$. Micrococcus folliculitis in HIV-1 disease. British Journal of Dermatology. 1999;141:558-61.

24. Smith K, Neafie R, Yeager J, \& Skelton H. Micrococcus folliculitis in HIV-1 disease. British Journal of Dermatology. 1999;141:558-61.

25. Ireland R. Oxford Dictionary of Dentistry. Oxford University Press, ed 2010.

26. American Dental Association. Sterilization and Disinfection of Dental Instruments. Accessed at: www.ada.org/ /media/ADA Member Center/Flles/cdc_sterilization.ashx; Accessed on: 01-08-2017.

27. Health Professional Council of South Africa. Booklet 6: Ethical Guidelines for management of Patients with HIV. Accessed at: www.hpcsa.co.za/PBPsychology/Guidelines; Accessed on: 28-07-2017.

28. Dublin Dental Council. Code of practice relating to infection control. Accessed at: dentalcouncil.ie/files/Infection Control. pdf - PDF file; Accessed on: 28-07-2017.

29. RutalaW, Weber, DJ. Guideline for Disinfection and Sterilization in Healthcare Facilities. Accessed at:https://www.cdc.gov/infectioncontrol/quidelines2008. 